JIIA, VOLUME 8 No. 2, MEI 2020

\title{
SIKAP DAN KEPUASAN KONSUMEN TERHADAP PEMBELIAN SATE DI KOTA BANDAR LAMPUNG
}

\author{
(Attitude and Satisfaction of Consumers Towards the Purchase of Satay in Bandar Lampung City) \\ Lika Oniaranti Sitorus, Ktut Murniati, Kordiyana K. Rangga \\ Jurusan Agribisnis, Fakultas Pertanian, Universitas Lampung, Jl. Prof. Dr. Soemantri Brojonegoro No.1 \\ Bandar Lampung 35141,e-mail: ktut.murniati@fp.unila.ac.id
}

\begin{abstract}
The study aims to analyze consumer attitudes, consumer satisfaction and the influence of consumer attitudes and satisfaction to the purchase of satay. Data were collected in June-July 2018. The research location is determined purposively with the consideration that the LWS and HJA Restaurants were established in the same year but they have different business development. There are 60 respondents collected using accidental sampling. The analytical methods used are Fishbein Multi-attribute Analysis and Customer Satisfaction Index (CSI). The results showed that consumers of LWS and HJA Restaurants have attitude of trust in products and service attributes. Consumers feel very satisfied with the purchase of satay at LWS and HJA Restaurants. The majority of consumers kept buying satay at LWS and HJA Restaurants even though the price of satay increased.
\end{abstract}

Key words: attitude, consumer satisfaction, satay

\section{PENDAHULUAN}

Gaya hidup masyarakat kota pada era moderenisasi ini semakin kompleks, yang dapat dilihat dari tingginya tingkat konsumsi dan standar hidup, revolusi teknologi, revolusi pengetahuan dan hubungan sosial. Masyarakat yang tinggal di perkotaan cenderung lebih banyak mengkonsumsi makanan jadi dan cepat saji yang merupakan dampak dari perubahan gaya hidup yang mengarah kepada gaya hidup kebarat-baratan (western lifestyle) dan intensitas kesibukan masyarakat perkotaan yang lebih tinggi dibandingkan masyarakat pedesaan (Ayuniyah, Indriani, dan Rangga 2015).

Rumah makan yang dipilih oleh masyarakat biasanya akan disesuaikan dengan status sosialnya. Keadaan ini membuat orang-orang tertarik untuk menekuni bisnis kuliner serta menuntut pelaku bisnis untuk selalu memberikan inovasi baru yang dapat menarik perhatian konsumen. Konsumen yang menginginkan inovasi baru di bidang kuliner dalam memilih makanan, tidak hanya mempertimbangkan jenis makanan yang akan dikonsumsi, namun juga memperhatikan pelayanan yang diberikan oleh produsen. Karakteristik fisik rumah makan digunakan untuk membangun kesan positif dibenak konsumen misalnya lokasi, tempat, dan pelayanan. Setiap rumah makan memiliki penampilan yang berbeda-beda yang sesuai dengan pasar sasarannya (Sulfiana, Murniati, dan Indriani 2018).

Peluang bisnis di bidang kuliner saat ini semakin berkembang pesat. Hal ini dikarenakan oleh naiknya tingkat pendapatan masyarakat yang diikuti dengan meningkatnya kesibukan, sehingga mendorong permintaan masyarakat terhadap makanan siap saji semakin meningkat. Pebisnis tertarik membuka usaha di bidang kuliner, karena keuntungan yang akan diperoleh sangat menjanjikan. Berdasarkan daftar nama wajib pajak restoran yang diterbitkan oleh Badan Pengelola Pajak dan Retribusi Daerah (BPRD) Kota Bandar Lampung (2017) terdiri dari 20 kecamatan dan memiliki 538 rumah makan.

Rumah makan sate merupakan salah satu jenis usaha kuliner yang diminati oleh banyak kalangan masyarakat. Keadaan ini dapat dilihat dari banyaknya rumah makan sate yang berdiri di Bandar Lampung, sampai saat ini terdapat 27 rumah makan yang sudah memiliki bagunan tetap. Setiap rumah makan memiliki kelebihan yang merupakan ciri khas masing-masing rumah makan. Berkembangnya rumah makan sate tidak dapat diukur hanya karena memiliki umur berdiri yang lama. Misalnya Rumah Makan Sate HJA yang telah berdiri sejak tahun 1983, tetapi belum cukup berkembang yang dapat dilihat dari banyaknya penjualan per hari, belum memiliki karyawan, dan tempat usaha yang masih kecil. Namun 
sebaliknya, dari banyaknya rumah makan sate yang ada di Bandar Lampung, Rumah Makan Sate LWS yang telah berdiri sejak tahun 1983 merupakan rumah makan yang telah berkembang dengan baik, keadaan ini dapat dilihat dari banyaknya cabang yang telah dimiliki (10 cabang), banyaknya penjualan per hari, dan banyaknya jumlah karyawan.

Proses pengambilan keputusan oleh konsumen terhadap produk sate digolongkan atas lima tahapan yaitu pengenalan kebutuhan, pencarian informasi, evaluasi alternatif, proses pembelian dan perilaku pasca pembelian (Ariesta, Lestari, dan Sayekti 2016). Perilaku setelah pembelian suatu produk ditentukan oleh kepuasan atau ketidakpuasan akan suatu produk sebagai akhir dari proses penjualan. Konsumen akan memiliki harapan yang menjadi standar kualitas dan akan dibandingkan dengan fungsi atau kualitas produk sesungguhnya dirasakan konsumen. Perilaku konsumen adalah perilaku yang diperlihatkan konsumen dalam mencari, membeli, menggunakan, mengevaluasi, dan menghabiskan produk dan jasa yang mereka harapkan akan memuaskan kebutuhan mereka (Schiffman dan Kanuk 2010).

Sikap merupakan hal penting yang berkaitan dengan keputusan pembelian. Sikap ini berkaitan dengan kepercayaan serta perilaku dari seorang konsumen (Katz 2004). Konsumen yang suka atau bersikap positif terhadap suatu produk akan cenderung memiliki keinginan yang kuat untuk memilih dan membeli produk yang disukainya tersebut. Sebaliknya, kalau konsumen bersikap negatif terhadap suatu produk, maka biasanya tidak akan mempertimbangkan produk tersebut sebagai pilihan pembelian, bahkan tidak jarang akan menyampaikan ketidaksukaannya kepada teman, kerabat atau tetangganya (Suryani 2012).

Kepuasan merupakan suatu proses dinamis dan harus selalu dipantau secara berkala oleh perusahaan sebagai produsen, karena pada dasarnya kepuasan akan menghasilkan keuntungan bagi perusahaan. Salah satu cara untuk mengukur tingkat kepuasan konsumenya dapat dilihat dari kualitas/mutu baik dari suatu produk yang meliputi barang dan jasa. Apabila kualitas produk yang ditawarkan lebih besar dari harapan konsumen, maka konsumen akan merasa puas. Namun sebaliknya, jika kualitas yang ditawarkan lebih rendah dari harapan maka konsumen akan merasa tidak puas (Gadung, Zakaria, dan Murniati 2015). Terbentuknya kepuasan konsumen dapat dibedakan melalui penilaian terhadap atribut produk dan pelayanan (rasa, harga, kenyamanan tempat, dan lain-lain) yang akan disesuaikan dengan karakteristik konsumen (pendapatan dan pengetahuan terhadap produk). Penelitian ini bertujuan menganalisis sikap konsumen, tingkat kepuasan konsumen dan pengaruhnya terhadap pembelian sate di Rumah Makan LWS dan Rumah Makan HJA.

\section{METODE PENELITIAN}

Metode yang digunakan dalam penelitian ini adalah metode survei yang merupakan pengambil sampel dari satu populasi dan menggunakan kuesioner sebagai alat pengumpul data yang pokok. Penelitian ini dilakukan di Rumah Makan Sate LWS dan Rumah Makan Sate HJA. Lokasi penelitian berada di Jl. Ki Maja No. 27 (Way Halim) dan Jl. Gatot Subroto. Penentuan lokasi dilakukan secara sengaja (purposive) dan menjadi sampel dengan pertimbangan bahwa berdasarkan hasil prasurvei dari beberapa rumah makan yang ada di Bandar Lampung, Rumah Makan LWS dan Rumah Makan HJA memiliki umur berdiri yang sama dan cukup lama, tetapi memiliki perkembangan usaha yang cukup berbeda. Perkembangan rumah makan tidak dapat diukur hanya karena memiliki umur berdiri yang lama, tetapi bagaimana rumah makan sate tersebut mampu berkompetisi di bidang kuliner.

Konsumen yang menjadi responden merupakan konsumen yang pernah mengkonsumsi sate dalam tiga bulan terakhir. Jumlah responden mengikuti Sugiyono (2009) sebanyak 60 responden yang dipilih secara accidental sampling. Data yang digunakan dalam penelitian ini adalah data primer dan sekunder. Data primer merupakan data yang diperoleh dari hasil wawancara dengan konsumen menggunakan kuesioner, sedangkan data sekunder dari studi literatur dan atau pustaka lain yang berhubungan dengan penelitian.

Penelitian ini menggunakan analisis kuantitatif dan kualitatif. Analisis deskriptif kualitatif digunakan untuk mengetahui karakteristik konsumen. Analisis deskriptif kuantitatif digunakan dalam uji validitas, reliabilitas, Multiatribut Fishbein, dan CSI. Atribut-atribut yang menjadi bahan pertimbangan responden antara lain rasa, harga, aroma, tampilan, halal, variasi menu, lokasi tempat, kesigapan pelayan, area parkir, kenyamanan tempat, dan kebersihan. 
Berdasarkan uji kelayakan kuesioner yang dilakukan pada 30 responden melalui tingkat kepentingan dan tingkat kinerja dengan uji validitas dan reliabilitas, seluruh atribut memiliki nilai Corrected item total correlation di atas 0,20 sehingga atribut tersebut dinyatakan valid dan dapat dimasukkan kedalam atribut penelitian. Uji reliabilitas atribut memiliki angka Cronbach Alpa lebih besar dari 0,70 sehingga atribut tersebut dapat dikatakan reliable dan layak untuk digunakan.

Analisis model sikap Fishbein digunakan untuk menganalisis pengetahuan produk yang dimiliki konsumen dan sikap terhadap produk berkenaan dengan ciri atau atribut produk (Prasetijo dan Ihalauw 2005). Komponen $e_{i}$ mengukur evaluasi kepentingan atribut-atribut yang dimiliki oleh suatu objek, sedangkan $b_{i}$ mengukur kepercayaan konsumen terhadap atribut yang dimiliki oleh suatu objek. Secara simbolis, rumus model sikap Multiatribut Fishbein diformulasikan dalam rumus:

$A o=\sum_{i=1}^{n}$ ei.bi

Keterangan :

Ao $=$ Sikap keseluruhan konsumen terhadap objek yaitu Rumah Makan Sate LWS dan HJA

bi $=$ Kekuatan kepercayaan konsumen bahwa Rumah Makan Sate LWS dan HJA memiliki atribut $\mathrm{i}$

ei $=$ Evaluasi konsumen mengenai atribut $\mathrm{i}$

$\mathrm{n}=$ Atribut yang relevan

Mengidentifikasi atribut pelayanan dan tingkat kepuasan konsumen menggunakan analisis Customer Satisfaction Index (CSI) yang merupakan ukuran keterkaitan konsumen terhadap suatu produk dan untuk mengukur indeks kepuasan konsumen dari tingkat kepentingan dan tingkat kinerja (Supranto 2006) Skala likert merupakan indikator skala pengukuran kepuasan konsumen pada kuesioner. Tahapan dalam pengukuran CSI yaitu:

1. Menghitung Weighted Factor (WF), yaitu mengubah nilai rata-rata kepentingan menjadi angka persentase dari total rata-rata tingkat kinerja seluruh atribut yang diuji.

2. Menghitung Weighted Score (WS), yaitu nilai perkalian antara nilai rata-rata tingkat kinerja masing-masing atribut dengan WF masingmasing atribut.

3. Menghitung Weighted Total (WT), yaitu menjumlahkan WS dari semua atribut.
4. Menghitung Satisfaction Index yaitu WT dibagi skala maksimum yang digunakan. Penelitian ini skala maksimum digunakan adalah 5 kemudian dikalikan 100 persen.

Metode tersebut sesuai dengan penelitian yang dilakukan oleh Bangun, Indriani, dan Soelaiman (2017) tentang sikap dan kepuasan konsumen Rumah Makan Ayam Penyet Hang Dihi Bandar Lampung.

\section{HASIL DAN PEMBAHASAN}

Rumah Makan LWS menawarkan jenis sate khas Solo dengan bahan baku bumbu dari 14 jenis rempah. Rumah makan sate ini terus berkembang dan keberhasilannya menarik perhatian konsumen, sehingga sampai saat ini memiliki 10 cabang rumah makan dan 30-35 orang karyawan. Rumah Makan LWS menawarkan harga sate per porsi Rp30.000,00 - Rp40.000,00. Bahan baku daging yang diolah di rumah makan ini per harinya berasal dari 30-40 kg daging kambing dan 70 ekor daging ayam. Pengolahan daging di Rumah Makan LWS dari $1 \mathrm{~kg}$ menghasilkan 40 tusuk sate, setiap tusuk sate berisi 4 potong daging sebesar ibu jari.

Rumah Makan HJA menawarkan jenis sate khas Madura. Pengelolaan sate hingga penjualan kepada konsumen dilakukan langsung oleh pemiliki. Rumah Makan HJA harga sate yang ditawarkan per porsi Rp22.000,00 - Rp25.000,00. Bahan baku daging yang diolah di rumah makan ini perharinya berasal dari $1-1,50 \mathrm{~kg}$ daging kambing dan $2-3$ ekor ayam. Pengolahan daging dari $1 \mathrm{~kg}$ menghasilkan 80 tusuk sate, setiap tusuk sate berisi 4 potong daging dan hati ayam.

\section{Proses Pengambilan Keputusan Konsumen dalam Pembelian Sate di Rumah Makan LWS dan Rumah Makan HJA}

Pengambilan keputusan konsumen merupakan tahap pengenalan kebutuhan dari dalam diri konsumen. Sumber informasi yang paling banyak didapatkan oleh konsumen di Rumah Makan Sate LWS berasal dari keluarga/saudara, sedangkan di Rumah Makan HJA berasal dari teman. Mayoritas alasan konsumen mengkonsumsi sate di Rumah Makan LWS adalah rasa yang khas (daging yang empuk dan bumbu khas Solo), sedangkan di Rumah Makan HJA adalah melepas rasa lapar. Manfaat yang paling banyak dicari konsumen dari mengkonsumsi sate di Rumah Makan LWS adalah rasa sate yang enak dan khas, sedangkan di Rumah Makan HJA adalah melepas rasa lapar. 
Tabel 1. Pengambilan keputusan konsumen (responden) dalam pembelian sate.

\begin{tabular}{|c|c|c|c|c|c|}
\hline \multirow[b]{2}{*}{ No. } & \multirow{2}{*}{$\begin{array}{c}\text { Pengambilan } \\
\text { Keputusan }\end{array}$} & \multicolumn{2}{|l|}{ RM LWS } & \multicolumn{2}{|l|}{ RM HJA } \\
\hline & & Mayoritas konsumen & $\begin{array}{l}\text { Persentase } \\
\quad(\%)\end{array}$ & Mayoritas konsumen & $\begin{array}{l}\text { Persentase } \\
(\%)\end{array}$ \\
\hline 1. & Sumber informasi & Keluarga/saudara & 40,00 & Teman & 60,00 \\
\hline 2. & Alasan mengkonsumsi & Rasa yang khas & 60,00 & Melepas rasa lapar & 36,67 \\
\hline 3. & Manfaat yang dicari & Rasa enak & 66,67 & Melepas rasa lapar & 43,33 \\
\hline 4. & Frekuensi pembelian & Dua minggu sekali & 36,67 & Dua minggu dan sebulan sekali & 33,33 \\
\hline 5. & Waktu pembelian & Sore hari (pukul 15.00-19.00) & 63,33 & Malam hari (pukul 19.00-21.00) & 96,67 \\
\hline 6. & Porsi pembelian & Satu porsi & 53,33 & Satu porsi & 70,00 \\
\hline 7. & $\begin{array}{l}\text { Pembelian menu } \\
\text { tambahan }\end{array}$ & Membeli menu tambahan & 70,00 & Membeli menu tambahan & 56,67 \\
\hline 8. & Perbedaan utama & Rasa enak, rasa khas & 53,33 & Pelayanan memuaskan & 43,33 \\
\hline 9. & $\begin{array}{l}\text { Kondisi ketika tidak } \\
\text { mengkonsumsi sate }\end{array}$ & Biasa saja & 70,00 & Biasa saja & 96,67 \\
\hline
\end{tabular}

Mayoritas frekuensi pembelian sate di Rumah Makan LWS adalah dua minggu sekali dan di Rumah Makan HJA dua minggu sekali serta sebulan sekali. Konsumen melakukan pembelian sate di Rumah Makan LWS biasanya pada sore hari (pukul 15.00-19.00 WIB). Hal ini dikarenakan konsumen yang berkunjung untuk membeli dan mengkonsumsi sate di Rumah Makan LWS pada saat pulang kerja. Pada Rumah Makan HJA, konsumen biasanya melakukan pembelian pada malam hari (pukul 19.00-21.00 WIB). Banyaknya porsi sate yang dibeli konsumen di Rumah Makan LWS dan Rumah Makan HJA mayoritas membeli satu porsi agar responden tidak merasa bosan dan dapat melakukan pembelian sate kembali.

Konsumen yang berkunjung ke Rumah Makan LWS dan Rumah Makan HJA tidak hanya membeli dan mengkonsumsi sate saja, melainkan mayoritas konsumen melakukan pembelian akan menu lain. Menu lain yang biasa dibeli oleh konsuman adalah sop dan tongseng. Mayoritas konsumen yang berkunjung ke Rumah Makan LWS merasakan adanya perbedaan utama pada rumah makan ini yaitu rasa yang enak dan khas. Rumah Makan HJA memiliki perbedaan utama dengan rumah makan sate lainnya adalah pelayanan yang memuaskan.

\section{Analisis Sikap Konsumen (Multiatribut Fishbein)}

Analisis model sikap Fishbein digunakan untuk menunjukan hubungan antara pengetahuan produk yang dimiliki konsumen dan sikap terhadap produk berkenaan dengan ciri atau atribut produk.
Tabel 2. Perhitungan Multiatribut Fishbein di Rumah Makan LWS.

\begin{tabular}{|c|c|c|c|}
\hline \multirow{2}{*}{ Atribut } & \multicolumn{3}{|c|}{ Skor Sikap (Ao) } \\
\hline & Evaluasi (ei) & (bi) & ei.bi \\
\hline Rasa & 1,70 & 4,83 & 8,22 \\
\hline Harga & 1,07 & 4,37 & 4,66 \\
\hline Aroma & 1,07 & 4,20 & 4,48 \\
\hline Tampilan & 0,97 & 4,13 & 4,00 \\
\hline Halal & 1,30 & 4,63 & 6,02 \\
\hline Variasi menu & 1,10 & 4,17 & 4,58 \\
\hline Lokasi tempat & 1,27 & 4,17 & 5,28 \\
\hline $\begin{array}{l}\text { Kesigapan } \\
\text { Pelayan }\end{array}$ & 1,20 & 4,17 & 5,00 \\
\hline Area parkir & 1,10 & 4,17 & 4,58 \\
\hline $\begin{array}{l}\text { Kenyamanan } \\
\text { tempat }\end{array}$ & 1,83 & 4,27 & 7,82 \\
\hline Kebersihan & 1,67 & 4,27 & 7,11 \\
\hline Total & & & 61,75 \\
\hline
\end{tabular}

Tabel 3. Perhitungan Multiatribut Fishbein di Rumah Makan HJA.

\begin{tabular}{lccc}
\hline \multirow{2}{*}{ Atribut } & \multicolumn{3}{c}{ Skor Sikap (Ao) } \\
\cline { 2 - 4 } & 1,70 & 4,80 & 8,16 \\
\cline { 2 - 4 } Rasa & 1,70 & 4,20 & 7,14 \\
Harga & 0,93 & 3,97 & 3,70 \\
Aroma & 0,80 & 4,13 & 3,31 \\
Tampilan & 1,00 & 4,53 & 4,53 \\
Halal & 0,97 & 3,97 & 3,83 \\
Variasi menu & 1,40 & 3,97 & 5,55 \\
Lokasi tempat & 1,63 & 3,97 & 6,48 \\
Kesigapan & 1,13 & 3,97 & 4,50 \\
Pelayan & 1,67 & 4,30 & 7,17 \\
Area parkir & 1,87 & 4,30 & 8,03 \\
Kenyamanan & & & 62,40 \\
tempat & & & \\
Kebersihan & &
\end{tabular}


Tabel 4. Perhitungan Customer Statisfaction Index (CSI) di Rumah Makan LWS.

\begin{tabular}{lcccc}
\hline Atribut & $\begin{array}{c}\text { Kepentingan Kepercayaan } \\
(\mathrm{ei})\end{array}$ & $\begin{array}{c}\text { Weight } \\
\text { Factor }\end{array}$ & $\begin{array}{c}\text { Weight } \\
\text { Score }\end{array}$ \\
\hline Rasa & 1,70 & 4,83 & 0,12 & 0,58 \\
Harga & 1,07 & 4,37 & 0,07 & 0,33 \\
Aroma & 1,07 & 4,20 & 0,07 & 0,31 \\
Tampilan & 0,97 & 4,13 & 0,07 & 0,28 \\
Halal & 1,30 & 4,63 & 0,09 & 0,42 \\
Variasi menu & 1,10 & 4,17 & 0,08 & 0,32 \\
Lokasi tempat & 1,27 & 4,17 & 0,09 & 0,37 \\
Kesigapan & 1,20 & 4,17 & 0,08 & 0,35 \\
pelayan & 1,10 & 4,17 & 0,08 & 0,32 \\
Area parkir & 1,83 & 4,27 & 0,13 & 0,55 \\
Kenyamanan & 1,67 & 4,27 & 0,12 & 0,50 \\
tempat & 14,27 & 47,37 & 1,00 & 4,33 \\
Kebersihan & & & & $6,57 \%$ \\
\hline WT & & & & \\
\hline CSI & & &
\end{tabular}

Metode ini menggunakan rentang skala yaitu $0-20$ sangat tidak percaya, 21-40 tidak percaya, 41-60 cukup percaya, 61-80 percaya, dan 81-100 sangat percaya. Perhitungan Multiatribut Fishbein pada penelitian ini secara lengkap terdapat pada Tabel 2 dan Tabel 3.

Berdasarkan Tabel 2 dan 3, sikap responden di Rumah Makan LWS dan Rumah Makan HJA mendapatkan nilai sikap relatif sama yang berada pada rentang 61-80 yaitu percaya. Hal ini menunjukan bahwa kedua rumah makan telah disukai oleh konsumen dengan baik dan konsumen percaya terhadap atribut produk dan pelayanan yang ditawarkan di kedua rumah makan tersebut. Keunggulan nilai skor sikap (Ao) di Rumah Makan HJA pada kinerja atribut kebersihan, harga, kesigapan pelayan, dan lokasi tempat, sedangkan di Rumah Makan LWS nilai skor sikap (Ao) unggul pada kinerja atribut rasa, kenyamanan tempat, halal, variasi menu, area parkir, aroma, dan tampilan. Konsumen lebih memprioritaskan atribut rasa dibandingkan atribut lainnya, sedangkan atribut yang tidak dapat perhatian lebih adalah atribut tampilan.

\section{Analisis Tingkat Kepuasan Konsumen (CSI)}

Customer Satisfaction Index (CSI) adalah metode yang digunakan untuk mengukur tingkat kepuasan konsumen secara keseluruhan dengan memperhatikan tingkat kepentingan dan tingkat kinerja. Rentang skala pada metode ini yaitu 0-20 sangat tidak puas, $21-40$ tidak puas, $41-60$ cukup
Tabel 5. Perhitungan Customer Statisfaction Index (CSI) di Rumah Makan HJA.

\begin{tabular}{lcccc}
\hline Atribut & $\begin{array}{c}\text { Kepentingan Kepercayaan } \\
(\mathrm{ei})\end{array}$ & $\begin{array}{c}\text { Weight } \\
\text { (bi) }\end{array}$ & $\begin{array}{c}\text { Weight } \\
\text { Factor }\end{array}$ \\
\hline Rasa & 1,70 & 4,80 & 0,11 & 0,55 \\
Harga & 1,70 & 4,20 & 0,11 & 0,48 \\
Aroma & 0,93 & 3,97 & 0,06 & 0,25 \\
Tampilan & 0,80 & 4,13 & 0,05 & 0,22 \\
Halal & 1,00 & 4,53 & 0,07 & 0,31 \\
Variasi menu & 0,97 & 3,97 & 0,07 & 0,26 \\
Lokasi tempat & 1,40 & 3,97 & 0,09 & 0,38 \\
Kesigapan & 1,63 & 3,97 & 0,11 & 0,44 \\
pelayan & 1,13 & 3,97 & 0,08 & 0,30 \\
Area parkir & 1,67 & 4,30 & 0,11 & 0,48 \\
Kenyamanan & & & & \\
tempat & 1,87 & 4,30 & 0,13 & 0,54 \\
Kebersihan & 14,80 & 46,10 & 1,00 & 4,22 \\
\hline WT & & & & $84,32 \%$ \\
\hline CSI & & & & \\
\hline
\end{tabular}

puas, 61-80 puas, dan 81-100 sangat puas. Perhitungan CSI secara lengkap terdapat pada Tabel 4 dan Tabel 5.

Berdasarkan Tabel 4 dan 5, responden yang mengkonsumsi sate di Rumah Makan LWS dan Rumah Makan HJA sudah berada pada rentang skala 81-100 yang menunjukan bahwa konsumen merasa sangat puas terhadap atribut produk dan pelayanan yang ditawarkan di kedua rumah makan. Kepuasan setiap konsumen cukup bervariasi dengan mengganggap bahwa atribut yang menurut mereka penting.

Setiap konsumen yang mengkonsumsi sate di Rumah Makan LWS dan Rumah Makan HJA tidak sama dalam memberikan nilai untuk setiap atribut. Konsumen yang mengkonsumsi sate di Rumah Makan LWS menyatakan bahwa rasa dan kualitas sate yang ditawarkan di rumah makan ini cukup memberikan kepuasan kepada konsumennya. Konsumen yang mengkonsumsi sate di Rumah Makan HJA menyatakan bahwa harga sate sesuai dengan kualitas yang mereka terima.

Hasil penelitian ini berbeda dengan penelitian yang dilakukan oleh Pratama, Indriani dan Endaryanto (2017) bahwa nilai Custumer Satisfaction Index (CSI) pada konsumsi makanan pecel lele di Kota Bandar Lampung berada pada rentang 61-80 persen yang berarti bahwa secara keseluruhan konsumen telah merasa puas. 


\section{Kondisi Saat Perubahan Harga dan Peluang Pembelian Sate Kembali di Rumah Makan LWS dan Rumah Makan HJA}

Mayoritas konsumen tidak akan beralih ketika di Rumah Makan LWS dan Rumah Makan HJA mengalami perubahan harga sate dengan nilai masing-masing persentase 83,33 persen dan 70 persen. Keadaan ini dikarenakan bahwa konsumen merasa percaya akan kualitas sate yang ditawarkan oleh rumah makan ini serta pelayanan yang diberikan oleh pihak rumah makan.

Konsumen di Rumah Makan LWS dan Rumah Makan HJA akan melakukan pembelian sate kembali. Keadaan ini dapat dilihat dari tingginya persentase peluang pembelian sate kembali di masing-masing rumah makan, yaitu 96,67 persen dan 93,33 persen. Hal ini juga akan mempengaruhi tingkat penjualan sate di masingmasing rumah makan, sehingga konsumen yang merasa percaya dan puas akan keadaan yang ditawarkan Rumah Makan LWS dan Rumah Makan HJA dapat meningkatkan penjualan serta mampu bertahan dan bersaing dengan bisnis kuliner lainnya.

Konsumen yang merasa percaya terhadap rasa yang enak dan khas, harga yang sesuai dengan kualitas, variasi menu yang ditawarkan, lokasi tempat yang strategis, kesigapan pelayan, tersedianya area parkir, kenyamanan tempat, dan kebersihan Rumah Makan LWS dan Rumah Makan HJA. Kepercayaan konsumen terhadap Rumah Makan LWS dan Rumah Makan HJA akan mempengaruhi sebaran informasi. Semakin konsumen merasa percaya terhadap rumah makan, maka semakin besar pula peluang penyebaran informasi.

\section{KESIMPULAN}

Konsumen memiliki sikap percaya terhadap atribut produk dan pelayanan yang ditawarkan di Rumah Makan Sate LWS dan Rumah Makan Sate HJA. Konsumen merasa sangat puas terhadap pembelian sate di Rumah Makan LWS dan Rumah Makan HJA. Pendapatan konsumen akan mempengaruhi pola konsumsi yang membentuk sikap dan tingkat kepuasan yang berbeda. Konsumen yang mengkonsumsi sate di Rumah Makan LWS memiliki pendapat kategori cukup tinggi, sehingga tidak mempermasalahkan harga, tetapi lebih mengutamakan kualitas sate yang ditawarkan. Konsumen yang mengkonsumsi sate di Rumah Makan HJA memiliki pendapatan kategori rendah, sehingga mempertimbangkan harga sate. Mayoritas konsumen sebesar 77 persen menyatakan tidak beralih ketika harga pada produk sate mengalami peningkatan dan akan melakukan pembelian sate kembali.

\section{DAFTAR PUSTAKA}

Ariesta W, DAH Lestari, WD Sayekti, dan RH Ismono. 2016. Perilaku konsumen dan strategi pengembangan agroindustri Beras Siger Tunas Baru di Kelurahan Pinang Jaya Kemiling Kota Bandar Lampung. JIIA, 4 (3) : 326-334. http://jurnal.fp.unila. ac.id/index. php/JIA/article/view/1508/1362. [6 Oktober 2018].

Ayuniyah Q, Y Indriani, dan KK Rangga. 2015. Ketersediaan dan perilaku konsumsi makanan jajanan olahan siswa sekolah dasar di Bandar Lampung. JIIA, 3 (4) : $409-418$. http://jurnal.fp.unila.ac.id/index.php/JIA/ article/view/1091/996. [6 Oktober 2018].

Badan Pengelola Pajak dan Retribusi Daerah (BPRD) Kota Bandar Lampung. 2017. Daftar Nama Wajib Pajak Restoran di Kota Bandar Lampung. BPRD Kota Bandar Lampung. Bandar Lampung.

Bangun YF, Y Indriani, dan A Soelaiman. 2017. Sikap dan kepuasan konsumen Rumah Makan Ayam Penyet Hang Dihi Bandar Lampung. JIIA, 5 (1) : 101-108. http://jurnal.fp.unila. ac.id/index.php/JIA/article/download/1680/1 506 [4 November 2017].

Gadung A, WA Zakaria, dan K Murniati. 2015. Analisis kepuasan dan loyalitas konsumen Kopi Bubuk Sinar Baru Cap Bola Dunia (Sb-Cbd) di Kota Bandar Lampung. JIIA, 3 (4) : 370-376. http://jurnal.fp.unila. ac.id/ index.php/JIA/article/view/1086/991 . [6 Oktober 2018].

Katz D. 2004. The functional Approach to the study of Attitudes. Gramedia. Jakarta.

Kotler. 2001. Manajemen Pemasaran di Indonesia: Analisis, Perencanaan, Implementasi dan Pengendalian. Salemba Empat. Jakarta.

Prasetijo R dan J Ihalauw. 2005. Perilaku Konsumen. Penerbit Andi. Yogyakarta.

Pratama DY, Y Indriani, dan T Endaryanto. 2017. Sikap dan kepuasan konsumen terhadap konsumsi pecel lele di dua rumah makan kota bandar lampung. JIIA, 5 (2): 200-205. http://jurnal.fp.unila.ac.id/index.php.JIA/arti cle/view/1659/1485. [6 November 2017]. 
JIIA, VOLUME 8 No. 2, MEI 2020

Schiffman LG and LL Kanuk. 2010. Consumer Behaviour (10 thedition). New Jersey. Pearson Prentice Hall.

Sugiyono. 2009. Metode Penelitian Kuantitatif, Kualitatif, dan $R \& D$. Alfabeta. Bandung.

Sulfiana WN, K Murniati, Y Indriani. 2018. Sikap dan kepuasan konsumen terhadap paket menu lele terbang, kaitannya dengan bauran pemasaran di Rumah Makan Sambal Lalap
Bandar Lampung. JIIA, 6 (1) : $72-78$. http://jurnal.fp.unila.ac.id/index.php/JIA/arti cle/view/2501/2185. [6 Oktober 2018].

Supranto J. 2006. Pengukuran Tingkat Kepuasan Pelanggan untuk Menaikkan Pangsa Pasar. PT Rineka Cipta. Jakarta.

Suryani. 2012. Perilaku Konsumen Implikasi Pada Strategi Pemasaran. Graha Ilmu. Yogyakarta. 